\title{
RESEARCH
}

Open Access

\section{Natural history of X-linked hypohidrotic ectodermal dysplasia: a 5-year follow-up study}

Sigrun Wohlfart ${ }^{1 *} \mathbb{D}$, Ralph Meiller², Johanna Hammersen', Jung Park', Johannes Menzel-Severing ${ }^{3}$, Volker O. Melichar', Kenneth Huttner ${ }^{4}$, Ramsey Johnson ${ }^{4}$, Florence Porte ${ }^{5}$ and Holm Schneider ${ }^{1}$

\begin{abstract}
Background: X-linked hypohidrotic ectodermal dysplasia (XLHED) is caused by pathogenic variants of the gene EDA disrupting the prenatal development of ectodermal derivatives. Cardinal symptoms are hypotrichosis, lack of teeth, and hypo- or anhidrosis, but the disease may also evoke other clinical problems. This study aimed at investigating the clinical course of XLHED in early childhood as the basis for an evaluation of the efficacy of potential treatments.

Methods: 25 children (19 boys and 6 girls between 11 and 35 months of age) with genetically confirmed XLHED were enrolled in a long-term natural history study. Clinical data were collected both retrospectively using parent questionnaires and medical records (pregnancy, birth, infancy) and prospectively until the age of 60 months. General development, dentition, sweating ability, ocular, respiratory, and skin involvement were assessed by standardized clinical examination and yearly quantitative surveys.

Results: All male subjects suffered from persistent anhidrosis and heat intolerance, although a few sweat ducts were detected in some patients. Sweating ability of girls with XLHED ranged from strongly reduced to almost normal. In the male subjects, 1-12 deciduous teeth erupted and 0-8 tooth germs of the permanent dentition became detectable. Tooth numbers were higher but variable in the female group. Most affected boys had no more than three if any Meibomian glands per eyelid, most girls had fewer than 10. Many male subjects developed additional, sometimes severe health issues, such as obstructive airway conditions, chronic eczema, or dry eye disease. Adverse events included various XLHED-related infections, unexplained fever, allergic reactions, and retardation of psychomotor development.

Conclusions: This first comprehensive study of the course of XLHED confirmed the early involvement of multiple organs, pointing to the need of early therapeutic intervention.
\end{abstract}

Keywords: Hypohidrotic ectodermal dysplasia, Natural history, Ectodysplasin A, Oligodontia, Dry eye, Heat intolerance

\footnotetext{
*Correspondence: sigrun.wohlfart@uk-erlangen.de

${ }^{1}$ Center for Ectodermal Dysplasias \& Department of Pediatrics, University

Hospital Erlangen, Loschgestr. 15, 91054 Erlangen, Germany

Full list of author information is available at the end of the article
}

(C) The Author(s). 2020 Open Access This article is distributed under the terms of the Creative Commons Attribution 4.0 International License (http://creativecommons.org/licenses/by/4.0/), which permits unrestricted use, distribution, and reproduction in any medium, provided you give appropriate credit to the original author(s) and the source, provide a link to the Creative Commons license, and indicate if changes were made. The Creative Commons Public Domain Dedication waiver (http://creativecommons.org/publicdomain/zero/1.0/) applies to the data made available in this article, unless otherwise stated. 


\section{Background}

The term ectodermal dysplasia (ED) refers to a heterogeneous group of rare congenital conditions affecting the normal development of ectodermal structures including skin, teeth, hair, nails, and eccrine glands [1]. X-linked hypohidrotic ectodermal dysplasia (XLHED; MIM \#305100), the most common form of ED, is characterized by a clinical triad of hypotrichosis, hypo-, oligo- or anodontia, and hypo- or anhidrosis [2]. The lack of sweat glands may lead to life-threatening hyperthermia which is mainly observed in early childhood [3]. The deficient development of other eccrine glands (salivary, lacrimal, sebaceous, submucosal, Meibomian, and mammary glands) entails recurrent respiratory infections, atrophic rhinitis, chronic skin issues, keratoconjunctivitis sicca, and, in case of females, breastfeeding difficulties [4-7].

XLHED is caused by variants of the X-chromosomal ectodysplasin A gene (EDA; NM_001399.4) leading to loss or dysfunction of the signaling protein EDA1 [8]. More than 200 different variants of this gene have been published so far, most of which are null mutations $[9,10]$. A certain single-nucleotide polymorphism (SNP) rs3827760 (c.1109T4C; p.Val370Ala) in the gene EDA1R, a gain-offunction allele associated with hair thickness and shovelshaped incisors that predominantly occurs in the Native American and East Asian population, was found to attenuate the severity of symptoms in at least one familial case of XLHED [11, 12].

More recently, our group reported successful prenatal treatment of XLHED in three boys with EDA null mutations by intra-amniotic administration of a replacement protein that induced the development of functional sweat glands, Meibomian glands and additional tooth germs [13]. The assessment of the natural history of a disease is indispensable for any evaluation of the efficacy of a potential treatment. In a series of exploratory studies conducted during the last 10 years, we captured patient-reported medical history data in subjects with genetically confirmed XLHED and tested minimally invasive methods for endpoint [14-20]. These cross-sectional studies have elucidated specific aspects of XLHED, provided new insights into the full spectrum of the phenotype and greater clarity about genotype-phenotype correlations. Validation of these findings, however, required the comprehensive collection and monitoring of clinical data over time, combined with repeated and objective endpoint assessments. Therefore, a long-term natural history study was initiated to compile systematically data on all XLHED-related clinical issues in untreated patients until the age of five years.

\section{Subjects and methods}

\section{Study design and patients}

19 male and 6 female patients between 11 and 35 months of age with genetically confirmed diagnosis of
XLHED were enrolled in a long-term natural history study at our site (www.clinicaltrials.gov; NCT02099552) and completed this study. The protocol included the retrospective collection of clinical data using parent questionnaires and medical records, standardized systematic clinical examinations both at the time of enrolment and at the age of five years, repeated facial photographs, and yearly interrogations of the parents with a quantitative phone survey plus gathering of all relevant medical documents during the course of the study. Final data analysis was conducted at the age of 5 years when all deciduous teeth should have erupted and tooth germs of the permanent dentition except molars M3 (wisdom teeth) are expected to be calcified sufficiently to be detectable in panoramic radiographs.

Written informed consents of both parents (if available) to the participation of their child in this study were obtained. The study was approved by an independent institutional ethics committee and conducted according to national regulations and GCP/ICH guidelines. Subjects were included only if they had not received any investigational treatment prior to enrolment. Further exclusion criteria were congenital anomalies outside of those considered to be associated with XLHED, known hypersensitivity to pilocarpine or pilocarpine-like drugs, and implantable electronic devices.

\section{DNA analysis}

Standard gene variant analysis including DNA extraction, polymerase chain reaction, and Sanger sequencing was performed as described previously [10]. Specific primer sequences and thermal cycling conditions for the detection of the XLHED-causing EDA mutations and screening for the polymorphism rs3827760 in EDA1R are available upon request.

\section{Anthropometric measurements and tooth quantification}

Anthropometric measurements were obtained retrospectively from the child's medical records or during the pediatric examinations. Body length in $\mathrm{cm}$, weight in $\mathrm{kg}$, and body mass index (BMI) in $\mathrm{kg} / \mathrm{m}^{2}$ were compared with standard percentiles for the normal population [21]. Dentition was assessed by oral examinations and a panoramic radiograph at the age of five years. Primary teeth and tooth germs of the permanent dentition which are well distinguishable based on crown size, morphology, and root length in the radiographs were quantified by experienced dentists.

\section{Assessment of sweat duct density and sweat production}

The number of plantar sweat ducts in a skin area of 36 $\mathrm{mm}^{2}$ was determined by confocal laser scanning microscopy with the VivaScope 1500 (Caliber Imaging \& Diagnostics, New York, USA) and extrapolated to an area of 1 
$\mathrm{cm}^{2}$. Sweating ability was assessed by quantification of pilocarpine-induced sweating (volumetry) in an area of 57 $\mathrm{mm}^{2}$ of the forearm for $30 \mathrm{~min}$ using the Wescor 3700 device (Wescor, Logan, USA) as described previously [13].

\section{Ophthalmic investigations}

Symptoms of XLHED-related chronic dry eye were assessed by an experienced ophthalmologist as described previously. This included corneal examinations for signs of keratitis by staining of the ocular surface, Meibography (transillumination of the lower eyelids for the detection of Meibomian gland openings; normal range: 20 to 30) [22], measurement of the tear film break-up time (BUT) with a threshold of 10 $\mathrm{s}$, determination of the ocular surface disease index (OSDI) score with a cutoff value of 12 and Schirmer's test for the quantification of tear production (placement of a filter paper in the lower lid and measuring its moisturization during 5 $\mathrm{min}$ ) with a cutoff value of $10 \mathrm{~mm}[16,17,23]$.

\section{Assessment of pulmonary function}

Pulmonary function tests for the detection of asthma and bronchial obstruction included measurements of

Table 1 EDA genotype of the study participants and data related to their sweating ability

\begin{tabular}{|c|c|c|c|c|c|c|}
\hline Code & $\begin{array}{l}\text { Age at enrolment } \\
\text { (months) }\end{array}$ & EDA variant & $\begin{array}{l}\text { Changes at the } \\
\text { amino acid level }\end{array}$ & $\begin{array}{l}\text { Pilocarpine-induced } \\
\text { sweat volume }(\mu \mathrm{L})\end{array}$ & $\begin{array}{l}\text { Sweat pores/ } \\
\mathrm{cm}^{2} \text { (plantar) }\end{array}$ & $\begin{array}{l}\text { Body temperature } \\
\left({ }^{\circ} \mathrm{C} \text {; average of }\right. \\
\text { independent } \\
\text { measurements })\end{array}$ \\
\hline
\end{tabular}

\begin{tabular}{|c|c|c|c|c|c|c|}
\hline \multicolumn{7}{|c|}{ Male subjects } \\
\hline M3-001 & 17 & c. $608 \mathrm{C}>\mathrm{T}$ & p.Pro203Leu & 0.0 & 22.2 & 37.15 \\
\hline M3-002 & 35 & c.467_468del & p.Arg156GInfsX2 & 0.0 & 1.4 & 36.90 \\
\hline M3-003 & 35 & $c .467 G>A$ & p.Arg156His & 0.0 & 0.0 & 36.95 \\
\hline M3-005 & 27 & c. $1075 \mathrm{~A}>\mathrm{T}$ & p.Lys359X & 0.0 & 0.0 & 37.25 \\
\hline M3-007 & 24 & $c .463 C>T$ & p.Arg155Cys & 0.0 & 5.6 & 37.10 \\
\hline M3-008 & 11 & c. $1133 C>T$ & p.Thr378Met & 0.0 & 0.0 & 36.90 \\
\hline M3-009 & 33 & C. $1141 G>C$ & p.Gly381Arg & 0.0 & 0.0 & 37.15 \\
\hline M3-012 & 22 & $c .467 G>A$ & p.Arg156His & 0.0 & 0.0 & 37.15 \\
\hline M3-013 & 27 & c.376_379del & p.Asp126ProfsX10 & 0.0 & 2.8 & 36.85 \\
\hline M3-014 & 33 & c.793G > T & splice-site alteration & 0.0 & 0.0 & 37.20 \\
\hline M3-015 & 17 & c. $925-3 C>G$ & splice-site alteration & 0.0 & 0.0 & 36.95 \\
\hline M3-016 & 21 & $c .502+1 G>A$ & splice-site alteration & 0.0 & 8.3 & 37.35 \\
\hline M3-017 & 28 & c. $463 \mathrm{C}>\mathrm{T}$ & p.Arg155Cys & 0.0 & 13.9 & 37.05 \\
\hline M3-018 & 29 & c. $467 \mathrm{G}>\mathrm{A}$ & p.Arg156His & 0.0 & 0.0 & 37.00 \\
\hline M3-019 & 26 & & duplication of exons $3-8$ & 0.0 & 41.7 & 36.90 \\
\hline M3-020 & 31 & c. $1072 C>T$ & p.Gln358X & 0.0 & 0.0 & 36.50 \\
\hline M3-022 & 28 & c. $911 A>G$ & p.Tyr304Cys & 0.0 & 0.0 & 36.80 \\
\hline M3-023 & 17 & c.648_665del18 & p.Pro216_Gly221del & 0.0 & 0.0 & 36.65 \\
\hline M3-025 & 26 & c. $1133 C>T$ & p.Thr378Met & 0.0 & 0.0 & 37.05 \\
\hline Average & 25.63 & / & / & 0.00 & 5.05 & 36.99 \\
\hline SD & 6.73 & I & I & 0.00 & 10.67 & 0.21 \\
\hline \multicolumn{7}{|c|}{ Female subjects } \\
\hline F3-004 & 35 & $c .467 G>A$ & p.Arg156His & 23.0 & 625 & 37.20 \\
\hline F3-006 & 25 & c. $1112 \mathrm{~T}>\mathrm{A}$ & p.lle371Asn & 9.0 & u.a. & 37.05 \\
\hline F3-010 & 35 & c.572_589del & p.Pro191_Pro196del & 16.0 & u.a. & 37.00 \\
\hline F3-011 & 31 & c.659_676del & p.Pro220_Pro225del & 17.0 & 850 & 37.20 \\
\hline F3-021 & 31 & c. $1072 C>T$ & p.Gln358X & 22.0 & 825 & 37.05 \\
\hline F3-024 & 21 & c.546_581del36 & p.Asn185_Pro196del & 55.0 & 775 & 37.35 \\
\hline Average & 29.67 & & & 23.67 & 768.75 & 37.14 \\
\hline SD & 5.61 & & & 16.15 & 100.78 & 0.13 \\
\hline
\end{tabular}


forced vital capacity (FVC), forced expiratory flow over $1 \mathrm{~s}$ (FEV1), and exhaled nitric oxide (eNO) level (Additional file 1). The results of body plethysmography were assessed by an experienced pediatric pneumologist.

\section{Skin examination}

Potential skin issues were evaluated with quantitative patient surveys and the Eczema Area and Severity Index (EASI), a scoring system originally established for the assessment of extent and severity of atopic dermatitis. The EASI score for the whole body is the sum of scores for each of four defined body regions (head and neck, upper extremities, trunk, and lower extremities) and can range from 0 to a maximum 72 (0: free of symptoms; $1-5$ : mild; 6-22: moderate; 23-72: severe). The particular body scores were obtained by multiplying the sum of severity scores (0: none; 1 : mild; 2 : moderate; 3 : severe) of the four key symptoms (erythema, infiltration, excoriations, and lichenification) with the area score (ranging from 0 to 6; representative for the percentage of affected area for each region) and by multiplying the result with the constant value for each body region proportionate to its percentage of the body surface [24-26].

\section{Quantitative patient survey and statistical analysis}

The patients' parents were asked once a year to fill in a questionnaire referring to different clinical and social aspects of XLHED. These surveys focused on the evaluation of the child's sweating ability and (impaired) heat tolerance, XLHED-related issues with hair, teeth, eyes, nose and airways, voice, nutrition, skin, and nails. Continuous records of the various parameters including all data collected at the scheduled clinical examinations were analyzed. Box-and-whisker plots were used for the graphical depiction of the following statistical values: minimum, first quartile, median, third quartile and the maximum.

\section{Results}

The EDA genotypes of all subjects are listed in Table 1. None of them carried the SNP rs3827760 in EDA1R. Parent-reported details on the medical history of each child (parent questionnaires) confirmed the known spectrum of XLHED symptoms; information from medical records was added if required (Additional file 2). Although a few rudimentary sweat pores could be detected in some boys (Table 1), anhidrosis was a common feature of all male subjects investigated in this study. Pilocarpine-induced sweating, the parameter most relevant with respect to heat tolerance, became evident only in female subjects (average sweat volume of $23.7 \mu \mathrm{l}$ ). Figure 1 visualizes the differences in sweat gland endowment between trizygotic triplets: a girl with the normal number and distribution of sweat ducts, her sister
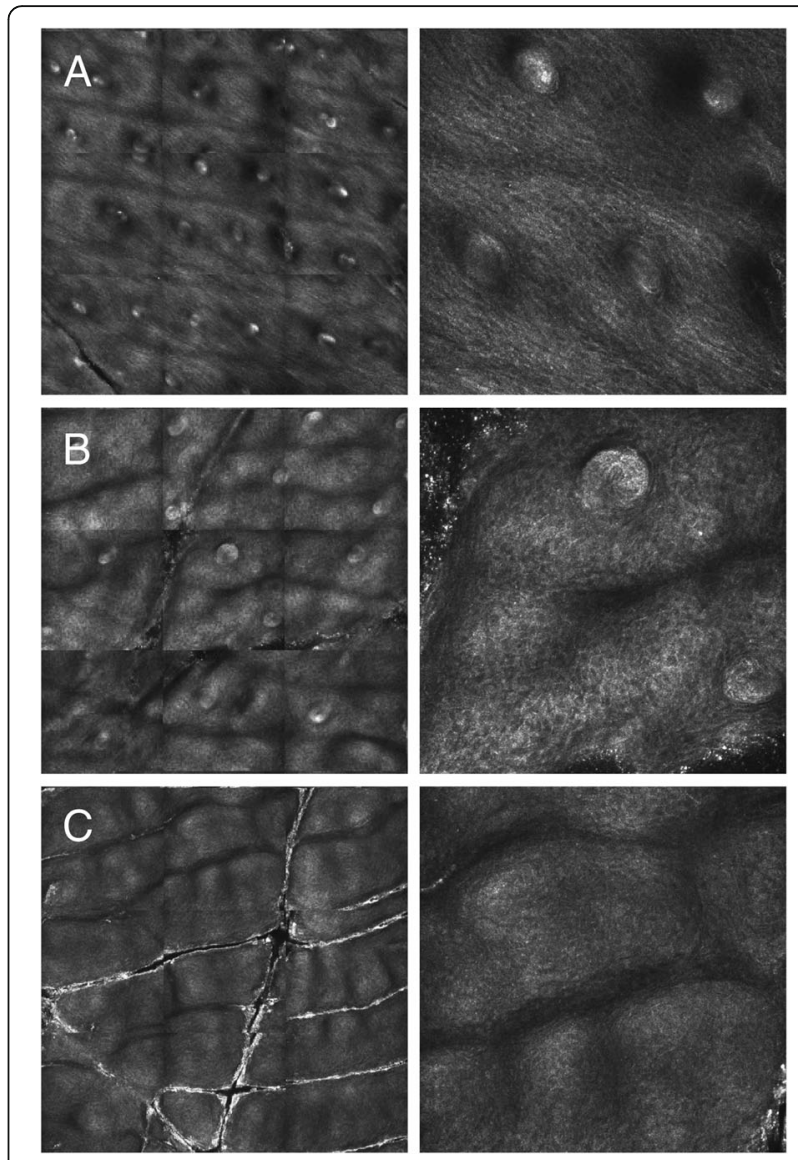

Fig. 1 Plantar sweat duct densities in trizygotic triplets as determined by confocal laser scanning microscopy. Left: plantar area of $2.25 \mathrm{~mm}^{2}$. Right: magnification of a representative section. a female triplet without EDA mutation. b subject F3-004,

heterozygous for the EDA variant c.467G > A. c subject M3-003, hemizygous for the indicated EDA variant

(subject F3-004, heterozygous carrier of the familial $E D A$ variant) with clearly fewer sweat ducts, and their brother (subject M3-003, hemizygous) who does not seem to have sweat glands at all. Average body temperatures measured during clinical examinations at the study site (Table 1) were similar for girls and boys with XLHED, whereas heat intolerance indicated by hyperthermic episodes prior to enrolment was reported for all male subjects but for none of the girls in our cohort (Table 2). In 7 of 19 subjects (37\%), unexplained fever led to hospitalization. Impaired thermoregulation had marked impact on daily life, outdoor sports, choice of vacation destinations, and the child's ability to travel (Table 2).

Physical examination revealed the known ED-related abnormalities (Table 3). Body length, weight and resultant BMI-for-age charts between birth and 5 years of age (Fig. 2) were delineated to detect potential developmental delays. Most boys with XLHED grew between the 
Table 2 History regarding heat intolerance prior to enrolment

\begin{tabular}{|c|c|c|c|c|c|c|c|c|c|}
\hline \multirow[t]{2}{*}{ Code } & \multirow{2}{*}{$\begin{array}{l}\text { Unexplained } \\
\text { fevers }\end{array}$} & \multirow{2}{*}{$\begin{array}{l}\text { Associated } \\
\text { seizures }\end{array}$} & \multirow{2}{*}{$\begin{array}{l}\text { Hospitalization } \\
\text { due to heat } \\
\text { intolerance }\end{array}$} & \multirow[t]{2}{*}{ If yes, diagnosis } & \multirow{2}{*}{$\begin{array}{l}\text { Reported heat } \\
\text { intolerance }\end{array}$} & \multicolumn{4}{|c|}{ Impact of heat intolerance/reduced sweating on: } \\
\hline & & & & & & $\begin{array}{l}\text { daily } \\
\text { life }\end{array}$ & $\begin{array}{l}\text { outdoor } \\
\text { sports }\end{array}$ & $\begin{array}{l}\text { choice of vacation } \\
\text { destinations }\end{array}$ & $\begin{array}{l}\text { ability to } \\
\text { travel }\end{array}$ \\
\hline \multicolumn{10}{|c|}{ Male subjects } \\
\hline M3-001 & Y & N & $\mathrm{N}$ & / & Y & $\mathrm{N}$ & N & Y & Y \\
\hline M3-002 & Y & N & Y & suspicion of pneumonia & Y & Y & N & Y & Y \\
\hline M3-003 & Y & N & N & / & Y & Y & N & Y & Y \\
\hline M3-005 & Y & N & Y & $\begin{array}{l}\text { therapy-resistant } \\
\text { hyperpyrexia }\end{array}$ & Y & Y & Y & Y & Y \\
\hline M3-007 & Y & N & N & / & Y & N & N & Y & Y \\
\hline M3-008 & Y & Y & Y & spasmodic laryngitis & Y & $\mathrm{N}$ & $\mathrm{N}$ & Y & Y \\
\hline M3-009 & Y & $\mathrm{N}$ & $\mathrm{N}$ & / & Y & $\mathrm{N}$ & $\mathrm{N}$ & Y & Y \\
\hline M3-012 & Y & N & Y & $\begin{array}{l}\text { suspicion of respiratory } \\
\text { tract infection }\end{array}$ & Y & $\mathrm{N}$ & N & Y & Y \\
\hline M3-013 & Y & $\mathrm{N}$ & $\mathrm{N}$ & / & Y & Y & $\mathrm{N}$ & Y & Y \\
\hline M3-014 & Y & N & N & / & Y & N & N & Y & Y \\
\hline M3-015 & Y & N & Y & hyperpyrexia & Y & Y & N & Y & Y \\
\hline M3-016 & N & N & N & / & Y & N & N & Y & Y \\
\hline M3-017 & Y & N & N & / & Y & Y & N & Y & Y \\
\hline M3-018 & Y & N & Y & fever, dehydration & Y & Y & Y & Y & Y \\
\hline M3-019 & Y & N & N & / & Y & N & Y & Y & Y \\
\hline M3-020 & Y & N & $\mathrm{N}$ & / & Y & Y & Y & Y & Y \\
\hline M3-022 & Y & $\mathrm{N}$ & $\mathrm{N}$ & I & Y & $\mathrm{N}$ & N & Y & Y \\
\hline M3-023 & Y & $\mathrm{N}$ & $\mathrm{N}$ & I & Y & $\mathrm{N}$ & $\mathrm{N}$ & Y & Y \\
\hline M3-025 & Y & N & Y & unexplained fever & Y & Y & Y & Y & Y \\
\hline \multicolumn{10}{|c|}{ Female subjects } \\
\hline F3-004 & N & N & $\mathrm{N}$ & I & $\mathrm{N}$ & $\mathrm{N}$ & N & $\mathrm{N}$ & $\mathrm{N}$ \\
\hline F3-006 & N & N & $N$ & / & N & N & N & $\mathrm{N}$ & $\mathrm{N}$ \\
\hline F3-010 & N & N & $\mathrm{N}$ & / & N & N & N & $\mathrm{N}$ & $\mathrm{N}$ \\
\hline F3-011 & $N$ & N & $N$ & / & $N$ & N & N & $\mathrm{N}$ & $\mathrm{N}$ \\
\hline F3-021 & N & N & $\mathrm{N}$ & / & $N$ & N & N & Y & N \\
\hline F3-024 & $\mathrm{N}$ & $\mathrm{N}$ & $\mathrm{N}$ & I & $\mathrm{N}$ & $\mathrm{N}$ & N & $\mathrm{N}$ & $\mathrm{N}$ \\
\hline
\end{tabular}

Abbreviations: $Y$ yes; $N$ no

Table 3 Physical exam findings

\begin{tabular}{lll}
\hline Detected abnormality & \multicolumn{1}{l}{ Number of affected individuals (\%) } \\
\cline { 2 - 3 } & Male subjects & $5(83)$ \\
\hline Hypo-, oligo- or anodontia (for more details see Table 4) & $19(100)$ & $19(100)$ \\
Lack or absence of eyebrows & $19(100)$ & $1(17)$ \\
Dry skin & $19(100)$ & $0(0)$ \\
Hypo- or atrichia & $17(89)$ & $0(0)$ \\
Sparse eyelashes & $16(84)$ & $1(17)$ \\
Hypoplastic jaws & $16(84)$ & $0(0)$ \\
Dysplastic or protruding ear(s) & $16(84)$ & $0(0)$ \\
Frontal bossing & $12(63)$ & $1(17)$ \\
Eklabium & $10(53)$ & $1(17)$ \\
Eczematous skin & $5(26)$ & $0(0)$ \\
Supernumerary nipple and/or nipples of different size & $4(21)$ & $0(0)$ \\
Initially retarded psychomotor development (later normal status) & $2(11)$ & $2(33)$ \\
Growth retardation & $2(11)$ & $0(0)$ \\
Conjunctivitis, inflamed lid margins & & \\
\hline
\end{tabular}




\section{A}
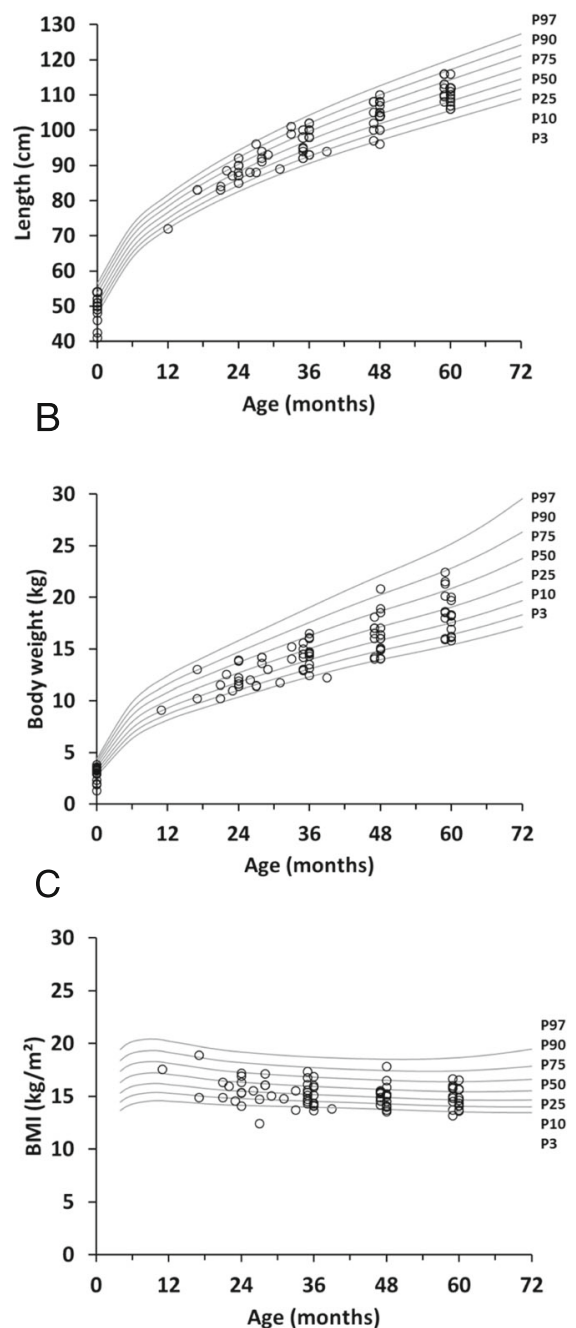

ㅇ
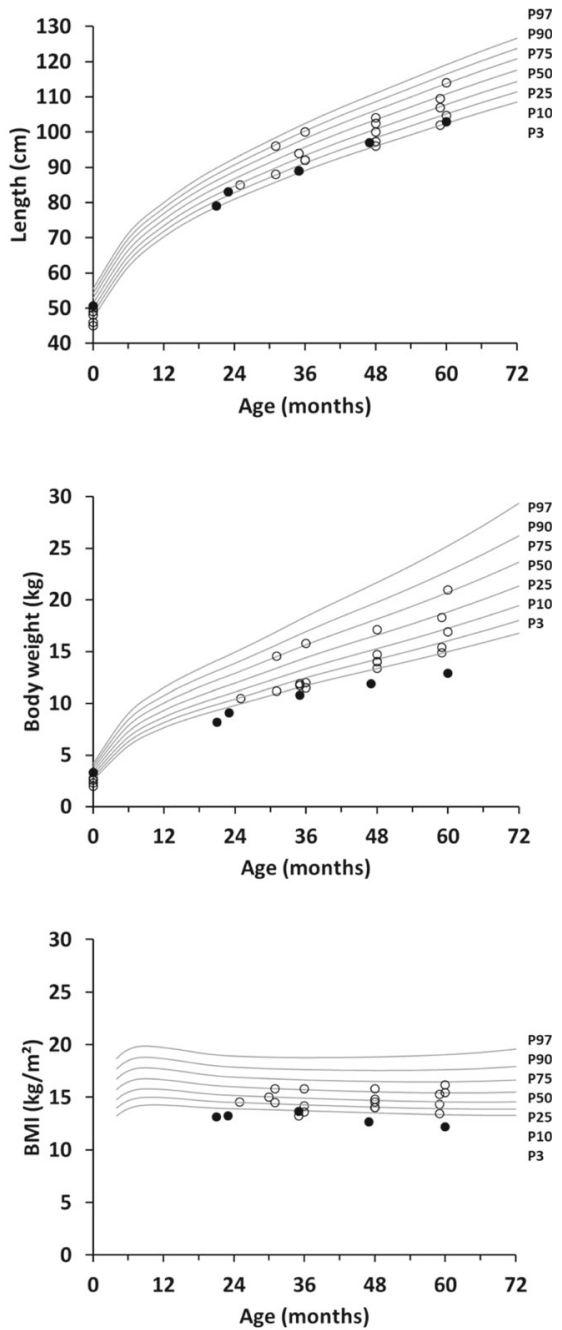

Fig. 2 Growth charts of subjects with XLHED between 0 and 60 months of age in comparison with standardized percentiles for the normal population depicting a length-for-age $(\mathrm{cm})$, b weight-for-age $(\mathrm{kg})$, and $\mathbf{c}$ BMI-for-age $\left(\mathrm{kg} / \mathrm{m}^{2}\right)$ [21]. The filled circles represent a girl from Israel with normal birth weight but obvious growth retardation later on

25th and the 75th percentiles (Fig. 2a). Four male subjects including three infants born prematurely had birth lengths below the third percentile, but only one of them fell below again at the age of 48 months. The girls showed normal growth, except for two pre-term babies with birth lengths below the third percentile (Fig. 2a). Body weights of most male and female subjects, however, did not reach the 50th percentile. Four of the boys (thereof three premature babies) and two preterm girls started with birth weights below the third percentile. One of the boys then showed clearly retarded weight gain and crossed the third percentile only at the age of 48 months (Fig. 2b). The weight of a female subject from Israel (born full-term with normal birth weight) fell below the third percentile and remained there until the last visit (Fig. 2b). The BMI-for-age chart reflects the slightly impaired weight gain of male and female subjects with XLHED: Five boys and three girls had a BMI below the P3 value at least at one time point during the 60 months (Fig. 2c). Head circumference and vital signs like blood pressure, heart rate, and respiratory rate were within the normal range in all subjects (data not shown).

The number of erupted teeth was assessed annually between the age of 24 and 60 months, which confirmed the significantly impaired and delayed dentition in children with XLHED (Fig. 3). As expected, final tooth counts in girls with XLHED (Table 4) were more variable than in affected boys who got 4.8 teeth on average (1.9 and 1.7 in the upper quadrants, 0.6 in each of the lower quadrants) 


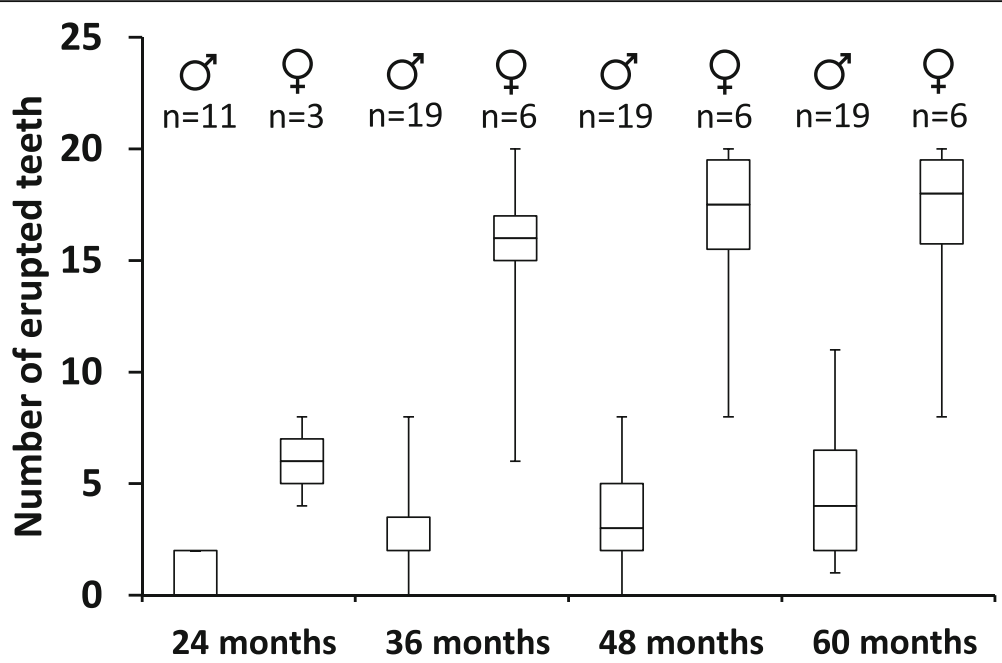

Fig. 3 Number of erupted teeth in male and female subjects with XLHED at the age of 24, 36, 48 and 60 months

until their fifth birthday when 20 teeth (5 per quadrant) are present in the normal population. Female subjects like F3-006 with only 8 erupted teeth at the age of 60 months, however, indicate that the dentition in girls can be affected as severely as in boys with XLHED. Tooth germs of the permanent dentition were quantified on panoramic radiographs at the last study visit by experienced dentists (Table 4). In the male cohort, 8 germs of permanent teeth were the maximum detected (when 28 should be visible, excluding the third molars), but three boys did not even have a single tooth bud. The total number of tooth germs in the female subjects was 21.5 on average (SD 5.43) with more even distribution over the quadrants (Table 4).

Ophthalmic investigations revealed bilateral superficial punctate keratitis, a consequence of chronic dry eye, in 7 of 18 boys with XLHED (39\%) but in none of the 6 girls (Table 5). All male subjects showed a significant lack or complete absence of Meibomian glands, the sole producers of the lipid components that stabilize the tear film on the ocular surface. Where more than 6 Meibomian gland openings per lower eyelid were detected (normal range: 20-30, median 26) [27], they appeared incompletely developed (Fig. 4). The number of Meibomian glands was reduced also in 4 of the 6 girls $(67 \%)$.

Sufficient tear film stability as indicated by a normal break-up time (BUT) on both eyes was observed only in three male subjects (Table 5); 11 of 14 boys (79\%) presented with diminished BUT values, and Ocular Surface Disease Index (OSDI) scores above the threshold of 12 suggested an early development of dry eye syndrome already in three of them. Schirmer's test, which could not be conducted on both eyes in all affected boys, still revealed normal values in 5 of 10 subjects (50\%). Two of the girls showed reduced BUT, but all had normal OSDI scores (Table 5).
Any adverse events (AEs) including serious adverse events (SAEs) that occurred during this study were documented thoroughly. In our cohort of male subjects with XLHED, 85 AEs (thereof 17 SAEs) were recorded, between 0 and 6 per year and individual, most of them XLHED-related infections (Table 6). The frequency and distribution of AEs was similar in the female subjects.

The annual phone visits and completed parent questionnaires also highlighted recurrent respiratory and skin problems. Upper airway infections were the most common issue; 22 children had to struggle with such problems (both sexes) and four of them (male patients) developed asthma. Furthermore, 22 children suffered from hoarseness of the voice (irrespective of sex). With the exception of two girls, all subjects were afflicted with dry skin, 15 of them also with eczema or atopic dermatitis. Every male but no female subject was reported to have a constantly blocked or running nose. Nosebleeds occurred frequently; 11 subjects had more than ten nosebleeds per year (ranging up to 36 events). In three children with eczematous skin lesions, the EASI scoring system was used and a maximum score of 10.1 was observed. Body plethysmography of 22 subjects and evaluation of their lung function parameters indicated obstructive airway conditions in seven boys with XLHED but in none of the female subjects.

\section{Discussion}

So far only one large collection of ED-related clinical issues has been published, the web-based Ectodermal Dysplasia International Registry (EDIR). It summarizes patient-reported medical data from 141 male and 82 female patients of different age groups (mean ages of 17.8 and 32.1 years, respectively). Self-assessment revealed life-long relevant health problems, not restricted to the 
Table 4 Number of deciduous teeth and tooth buds of the permanent dentition per quadrant

\begin{tabular}{|c|c|c|c|c|c|}
\hline Code & $\begin{array}{l}\text { Quadrant } \\
1\end{array}$ & $\begin{array}{l}\text { Quadrant } \\
2\end{array}$ & $\begin{array}{l}\text { Quadrant } \\
3\end{array}$ & $\begin{array}{l}\text { Quadrant } \\
4\end{array}$ & $\begin{array}{l}\text { Total } \\
\text { number } \\
\text { of teeth/ } \\
\text { tooth } \\
\text { buds }\end{array}$ \\
\hline
\end{tabular}

Male subjects

$\begin{array}{llllll}\text { M3-001 } & 2+1 & 2+1 & 1+0 & 0+0 & 5+2 \\ \text { M3-002 } & 1+2 & 0+2 & 0+0 & 0+0 & 1+4 \\ \text { M3-003 } & 1+2 & 1+2 & 0+2 & 0+1 & 2+7 \\ \text { M3-005 } & 1+0 & 1+0 & 0+0 & 0+0 & 2+0 \\ \text { M3-007 } & 3+2 & 3+2 & 3+1 & 3+1 & 12+6 \\ \text { M3-008 } & 3+3 & 3+3 & 1+1 & 1+1 & 8+8 \\ \text { M3-009 } & 2+2 & 2+1 & 1+1 & 1+1 & 6+5 \\ \text { M3-012 } & 2+1 & 2+0 & 0+0 & 0+0 & 4+1 \\ \text { M3-013 } & 1+2 & 1+2 & 0+1 & 0+1 & 2+6 \\ \text { M3-014 } & 3+2 & 3+2 & 0+1 & 1+1 & 7+6 \\ \text { M3-015 } & 3+1 & 1+1 & 0+0 & 0+0 & 4+2 \\ \text { M3-016 } & 3+2 & 3+2 & 0+1 & 0+1 & 6+6 \\ \text { M3-017 } & 3+2 & 3+3 & 2+0 & 2+0 & 10+5 \\ \text { M3-018 } & 1+2 & 1+2 & 0+0 & 0+1 & 2+5 \\ \text { M3-019 } & 1+0 & 1+1 & 0+0 & 0+0 & 2+1 \\ \text { M3-020 } & 2+2 & 2+2 & 1+1 & 1+1 & 6+6 \\ \text { M3-022 } & 2+0 & 2+0 & 0+0 & 0+0 & 4+0 \\ \text { M3-023 } & 1+0 & 1+0 & 1+1 & 1+1 & 4+2 \\ \text { M3-025 } & 1+0 & 1+0 & 1+0 & 1+0 & 4+0 \\ \text { Average } & 1.90+ & 1.74+ & 0.58+ & 0.58+ & 4.79+ \\ \text { SD } & 1.37 & 1.37 & 0.53 & 0.53 & 3.79 \\ & 0.88+ & 0.93+ & 0.84+ & 0.84+ & 2.94+ \\ & 0.96 & 1.01 & 0.61 & 0.51 & 2.64\end{array}$

Female subjects

\begin{tabular}{llllll} 
F3-004 & $4+5$ & $4+5$ & $5+6$ & $5+6$ & $18+22$ \\
F3-006 & $3+5$ & $1+3$ & $1+2$ & $3+3$ & $8+13$ \\
F3-010 & $5+6$ & $5+6$ & $5+7$ & $5+7$ & $20+26$ \\
F3-011 & $4+5$ & $3+3$ & $3+5$ & $5+5$ & $15+18$ \\
F3-021 & $5+7$ & $5+7$ & $5+7$ & $5+7$ & $20+28$ \\
F3-024 & $4+4$ & $4+4$ & $5+7$ & $5+7$ & $18+22$ \\
Average & $4.17+$ & $3.67+$ & $4.00+$ & $4.67+$ & $16.5+$ \\
& 5.33 & 4.67 & 5.67 & 5.83 & 21.5 \\
SD & $0.75+$ & $1.51+$ & $1.67+$ & $0.82+$ & $4.55+5.43$ \\
& 1.03 & 1.63 & 1.97 & 1.60 & \\
\hline
\end{tabular}

typical symptom triad but also regarding growth, skin, nails, respiratory, and ocular issues [28]. The natural history data reported here broaden the current knowledge about the clinical course of XLHED by focusing on the most critical first years of life when life-threatening hyperthermic events and complications of disease usually occur [3]. A higher degree of awareness among
Table 5 Ophthalmic assessments

\begin{tabular}{|c|c|c|c|c|c|c|c|c|}
\hline \multirow[t]{2}{*}{ Code } & \multirow[t]{2}{*}{$\begin{array}{l}\text { Corneal } \\
\text { examination }\end{array}$} & \multicolumn{2}{|c|}{$\begin{array}{l}\text { Meibomian } \\
\text { gland } \\
\text { openings }^{a}\end{array}$} & \multicolumn{2}{|c|}{ BUT (s) } & \multirow[t]{2}{*}{$\begin{array}{l}\text { OSDI } \\
\text { score }\end{array}$} & \multicolumn{2}{|c|}{$\begin{array}{l}\text { Schirmer's } \\
\text { test (mm) }\end{array}$} \\
\hline & & $\begin{array}{l}\text { Right } \\
\text { eye }\end{array}$ & $\begin{array}{l}\text { Left } \\
\text { eye }\end{array}$ & $\begin{array}{l}\text { Right } \\
\text { eye }\end{array}$ & $\begin{array}{l}\text { Left } \\
\text { eye }\end{array}$ & & $\begin{array}{l}\text { Right } \\
\text { eye }\end{array}$ & $\begin{array}{l}\text { Left } \\
\text { eye }\end{array}$ \\
\hline \multicolumn{9}{|c|}{ Male subjects } \\
\hline M3-001 & $\begin{array}{l}\text { SPK (on } \\
\text { both sides) }\end{array}$ & 1 & 2 & 3 & 3 & 11.1 & 12 & 10 \\
\hline M3-002 & $N$ & 0 & 0 & 3 & 2 & 0.0 & 5 & 6 \\
\hline M3-003 & $\begin{array}{l}\text { SPK (on } \\
\text { both sides) }\end{array}$ & 2 & 3 & 2 & 4 & 8.3 & u.a. & u.a. \\
\hline M3-005 & $N$ & 3 & 1 & 5 & 4 & 5.0 & 11 & 5 \\
\hline M3-007 & $N$ & 0 & 0 & 10 & 12 & 2.5 & u.a. & u.a. \\
\hline M3-008 & $\begin{array}{l}\text { SPK (on } \\
\text { both sides) }\end{array}$ & 2 & 3 & 1 & 2 & 13.8 & 20 & u.a. \\
\hline M3-009 & $N$ & 5 & 4 & 4 & 4 & 5.0 & 10 & 4 \\
\hline M3-012 & $N$ & 0 & 0 & u.a. & u.a. & 5.0 & 12 & 17 \\
\hline M3-013 & $\begin{array}{l}\text { SPK (on } \\
\text { both sides) }\end{array}$ & 1 & 3 & 5 & 5 & 11.1 & 6 & 11 \\
\hline M3-014 & $N$ & 1 & 1 & 10 & 11 & 5.0 & 7 & 4 \\
\hline M3-015 & u.a. & 0 & 3 & 5 & 6 & 8.3 & u.a. & u.a. \\
\hline M3-016 & $\begin{array}{l}\text { SPK (on } \\
\text { both sides) }\end{array}$ & 0 & 0 & 8 & 10 & 5.5 & u.a. & u.a. \\
\hline M3-017 & $N$ & 0 & 2 & 12 & 12 & 2.7 & 14 & $>25$ \\
\hline M3-018 & $\begin{array}{l}\text { SPK (on } \\
\text { both sides) }\end{array}$ & 1 & 2 & 4 & 4 & 19.4 & u.a. & u.a. \\
\hline M3-019 & $N$ & $6^{\mathrm{b}}$ & $9^{b}$ & 7 & u.a. & 2.7 & 16 & 10 \\
\hline M3-020 & $\begin{array}{l}\text { SPK (on } \\
\text { both sides) }\end{array}$ & 1 & 0 & u.a. & u.a. & 22.2 & u.a. & u.a. \\
\hline M3-022 & $N$ & 1 & 1 & u.a. & u.a. & 5.0 & u.a. & u.a. \\
\hline M3-023 & $N$ & 1 & 0 & u.a. & u.a. & 5.0 & u.a. & u.a. \\
\hline M3-025 & $N$ & 6 & 6 & u.a. & u.a. & 2.7 & $>25$ & $>25$ \\
\hline Average & / & 1.39 & 1.72 & 5.64 & 6.08 & 7.38 & / & / \\
\hline SD & / & 1.72 & 1.71 & 3.30 & 3.77 & 5.85 & / & / \\
\hline \multicolumn{9}{|c|}{ Female subjects } \\
\hline F3-004 & $\mathrm{N}$ & $>20$ & $>20$ & 14 & 14 & 0.0 & u.a. & u.a. \\
\hline F3-006 & $\mathrm{N}$ & 9 & 8 & 14 & 12 & 11.1 & u.a. & u.a. \\
\hline F3-010 & $\mathrm{N}$ & 8 & 5 & 8 & 6 & 2.5 & 4 & u.a. \\
\hline F3-011 & $\mathrm{N}$ & $>20$ & $>20$ & 9 & 8 & 2.5 & 10 & 5 \\
\hline F3-021 & $\mathrm{N}$ & 6 & 5 & 12 & 10 & 0.0 & $>25$ & $>25$ \\
\hline F3-024 & $\mathrm{N}$ & 5 & 5 & u.a. & u.a. & 0.0 & u.a. & u.a. \\
\hline
\end{tabular}

Abbreviations: ${ }^{\text {a }}$, maximum number detected in the lower lid during two independent examinations; N, normal; SPK, superficial punctate keratitis; u.a., unable to assess; ${ }^{\mathrm{b}}$, not fully developed

medical personnel, mainly pediatric dentists and pediatricians, would probably accelerate proper clinical diagnosis and thereby prevent heat-associated complications. In this respect, the parent-reported major impact of heat intolerance on different aspects of daily life, which was probably underappreciated in previous studies, seems to 

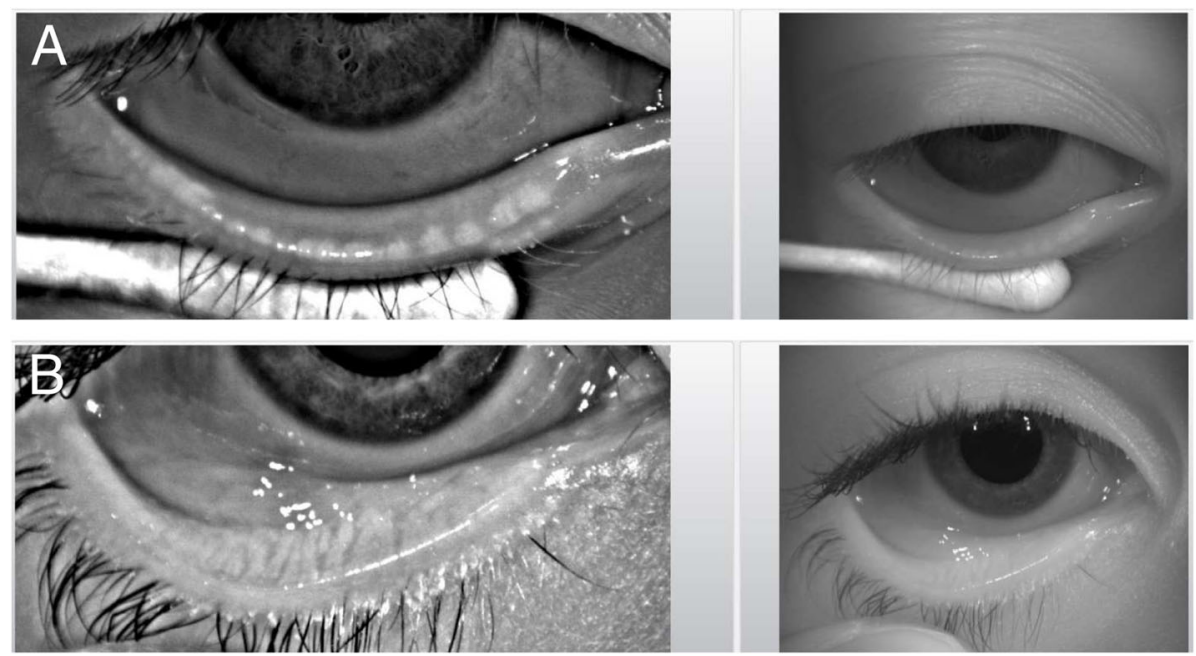

Fig. 4 a Infrared images of the everted lower eyelid highlight some rudimentary Meibomian gland ducts (white dots) in a representative male subject with XLHED. $\mathbf{b}$ more than 20 fully developed Meibomian gland ducts, extending from the lower tarsus to the orifices at the lid margin, in an age-matched healthy control

be of particular relevance. Our study confirms an EDassociated increased risk of growth retardation that was reported by others [29], although persistent undernourishment and developmental delay were not common in our cohort. Nevertheless, most of our patients were situated in the lower half of the growth charts, and it is conceivable that children growing up under conditions of poor nutrition or medical care (e.g. no provision of prostheses allowing proper mastication) are at higher risk of developmental retardation.

As expected, our female subjects with XLHED showed milder phenotypes than affected boys, but none of them was asymptomatic. Although females with XLHED used to be considered only as carriers in numerous publications, it has become well known that most of them are actually affected by XLHED-related symptoms like hypotrichosis, hypodontia, and conically shaped teeth (carrier detection is possible in at least 70\% of cases) [30]. Additional XLHED-related issues, such as deficient breast development and its consequences (breastfeeding difficulties and psychosocial problems), cannot be assessed before puberty but have been found to be frequent among female carriers of $E D A$ mutations [18]. Therefore, future medical treatment might also be considered for female patients.

Table 6 Adverse events (AEs) / serious adverse events (SAEs) during the observation period

\begin{tabular}{|c|c|c|c|c|c|c|}
\hline \multirow[b]{2}{*}{ Event } & \multicolumn{3}{|l|}{ Male subjects } & \multicolumn{3}{|l|}{ Female subjects } \\
\hline & Number of subjects (\%) & AEs & Thereof SAEs & Number of subjects (\%) & AEs & Thereof SAES \\
\hline \multicolumn{7}{|l|}{ 1. XLHED-related infections } \\
\hline Respiratory & $14(74)$ & 25 & 7 & $3(50)$ & 5 & 0 \\
\hline Ear & $4(21)$ & 15 & 3 & $1(17)$ & 6 & 0 \\
\hline Skin & $2(11)$ & 5 & 0 & $2(33)$ & 4 & 0 \\
\hline Nose & $4(21)$ & 4 & 0 & $1(17)$ & 1 & 0 \\
\hline Eye & $1(5)$ & 1 & 0 & $1(17)$ & 1 & 0 \\
\hline Other & $0(0)$ & 0 & 0 & $1(17)$ & 3 & 0 \\
\hline 2. XLHED-unrelated infections & $5(26)$ & 7 & 0 & $2(33)$ & 4 & 0 \\
\hline \multicolumn{7}{|l|}{ 3. Unexplained fevers } \\
\hline with seizure & $1(5)$ & 2 & 2 & $0(0)$ & 0 & 0 \\
\hline without seizure & $1(5)$ & 1 & 0 & $1(17)$ & 1 & 0 \\
\hline 4. Allergic reactions & $5(26)$ & 8 & 2 & $1(17)$ & 1 & 0 \\
\hline 5. Developmental retardation & $5(26)$ & 6 & 0 & $1(17)$ & 2 & 0 \\
\hline 6. Other & $6(32)$ & 11 & 3 & $1(17)$ & 5 & 2 \\
\hline
\end{tabular}


Phenotypic heterogeneity, however, was another feature of our female cohort, while genotype-phenotype correlation is rather strong in boys with XLHED [14, 20]. The latter may not be reflected fully by our randomly recruited cohort in which the minority of male subjects with hypomorphic mutations is not represented, but only solid natural history data may allow to predict the severity of XLHED for each known EDA variant. Skewed Xchromosome inactivation is likely to explain phenotypic differences between females with similar EDA variants and has been discussed in a few case reports [31-33].

Although this natural history study was completed in 2018, medical care of the patients at our center will continue, enabling further data collection until adulthood. Due to the sparse availability of data for rare diseases like XLHED, those studies may not only be valuable for genotype-based prediction of the course of disease and attempts to prevent complications, but also serve as comparators allowing the evaluation of future drug therapies [13, 34-36]. Considering the prospective nature, the duration of this study, and the number of patients followed, our data will be relevant for regulatory agencies who evaluate outcomes from open-label drug trials in subjects with XLHED.

\section{Conclusions}

This first comprehensive natural history study characterized the course of XLHED in male and female patients during the first five years of life, confirming the early involvement of multiple organs and pointing to the need of early therapeutic intervention. The data emphasize that null mutations in EDA consistently result in anhidrosis and severe heat intolerance, while the phenotypes of individuals who carry such mutations heterozygously show a remarkable variability. Although female subjects with one normal X chromosome are often less severely affected, they are not asymptomatic and should receive more attention by researchers in the field. Besides the classic symptom triad of XLHED, patients usually suffer from a number of additional clinical issues, such as skin, eye and respiratory problems that may also be amenable to early treatment.

\section{Supplementary information}

Supplementary information accompanies this paper at https://doi.org/10. 1186/s13023-019-1288-x

Additional file 1. Pulmonary Function Test (selected parameters). FVC $(\mathrm{L})$, FEV1 $(\mathrm{L})$ and eNO level (ppb).

Additional file 2. ED-related medical history. Reported abnormalities.

\section{Abbreviations}

BUT: Tear film break-up time; EASI: Eczema Area and Severity Index; ED: Ectodermal dysplasia; EDA: Ectodysplasin A; eNO: Exhaled nitric oxide; FEV1: Forced expiratory volume; FVC: Forced vital capacity;
HED: Hypohidrotic ectodermal dysplasia; OSDI: Ocular Surface Disease Index; SNP: Single-nucleotide polymorphism; SPK: Superficial punctate keratitis; XLHED: X-linked hypohidrotic ectodermal dysplasia

\section{Acknowledgements}

We are very grateful to the patient's families for participating in this study as well as to all members of the medical teams involved in their care, in particular Drs. Jasna Dietz, Silvia Maitz, Christina Jacobi, Susanne Queck, Katharina Bücher, and Andrea Fiedlschuster. Three of the authors of this publication are members of the European Reference Network (ERN) Skin, project ID number 739543

\section{Authors' contributions}

$\mathrm{KH}$ and RJ conceptualized and designed the study. SW and HS collected and evaluated data, drafted the initial manuscript, and reviewed and revised it. $\mathrm{RM}, J \mathrm{H}, \mathrm{JP}, \mathrm{JMS}, \mathrm{VOM}$, and FP collected data, carried out the initial analyses, and critically reviewed the manuscript for intellectual content. All authors approved the final manuscript as submitted and agree to be accountable for all aspects of the work.

\section{Authors' information}

$\mathrm{KH}$ and $\mathrm{RJ}$ were employees of Edimer Pharmaceuticals at the time this study was designed and started (until 2015). HS received initial research funding for the study from Edimer Pharmaceuticals. All other authors have no financial relationships relevant to this article to disclose.

\section{Funding}

This study was funded by Edimer Pharmaceuticals from 2014 to 2016 and by the National Foundation for Ectodermal Dysplasias (NFED) from 2017 to 2019.

Availability of data and materials

The datasets used and analysed during the current study are available from the corresponding author on reasonable request.

\section{Ethics approval and consent to participate}

The study was approved by an independent institutional ethics committee and registered as Natural History and Outcomes in X-Linked Hypohidrotic Ectodermal Dysplasia (ECP-015; https:/clinicaltrials.gov/ct2/show/study/ NCT02099552). Written informed consents of both parents (if available) to the participation of their child in this study were obtained.

\section{Consent for publication}

Not applicable.

\section{Competing interests}

The authors declare that they have no competing interests.

\section{Author details}

${ }^{1}$ Center for Ectodermal Dysplasias \& Department of Pediatrics, University Hospital Erlangen, Loschgestr. 15, 91054 Erlangen, Germany. ${ }^{2}$ Department of Ophthalmology, University of Erlangen-Nürnberg, Erlangen, Germany. ${ }^{3}$ Department of Ophthalmology, University of Düsseldorf, Düsseldorf, Germany. ${ }^{4}$ Edimer Pharmaceuticals, Cambridge, USA. ${ }^{5}$ EspeRare Foundation, Geneva, Switzerland.

Received: 13 September 2019 Accepted: 24 December 2019 Published online: 10 January 2020

References

1. Itin PH, Fistarol SK. Ectodermal dysplasias. Am J Med Genet C. 2004;131:4551.

2. Clarke A, Phillips DI, Brown R, Harper PS. Clinical aspects of X-linked hypohidrotic ectodermal dysplasia. Arch Dis Child. 1987;62:989-96.

3. Blüschke $G$, Nüsken $K D$, Schneider $H$. Prevalence and prevention of severe complications of hypohidrotic ectodermal dysplasia in infancy. Early Hum Dev. 2010;86:397-9.

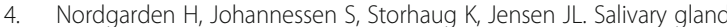
involvement in hypohidrotic ectodermal dysplasia. Oral Dis. 1998;4:152-4.

5. Kaercher T. Ocular symptoms and signs in patients with ectodermal dysplasia syndromes. Graefes Arch Clin Exp Ophthalmol. 2004;242:495-500. 
6. Al-Jassim AH, Swift AC. Persistent nasal crusting due to hypohidrotic ectodermal dysplasia. J Laryngol Otol. 1996;110:379-82.

7. Lindfors PH, Voutilainen M, Mikkola ML. Ectodysplasin/NF-kappaB signaling in embryonic mammary gland development. J Mammary Gland Biol Neoplasia. 2013;18:165-9.

8. Kere J, Srivastava AK, Montonen O, Zonana J, Thomas N, Ferguson B, et al. $X$-linked anhidrotic (hypohidrotic) ectodermal dysplasia is caused by mutation in a novel transmembrane protein. Nat Genet. 1996;13:409-16.

9. Trzeciak WH, Koczorowski R. Molecular basis of hypohidrotic ectodermal dysplasia: an update. J Appl Genet. 2016;57:51-61.

10. Wohlfart S, Hammersen J, Schneider H. Mutational spectrum in 101 patients with hypohidrotic ectodermal dysplasia and breakpoint mapping in independent cases of rare genomic rearrangements. J Hum Genet. 2016;61: 891-7.

11. Mou C, Thomason HA, Willan PM, Clowes C, Harris WE, Drew CF, et al. Enhanced ectodysplasin-a receptor (EDAR) signaling alters multiple fiber characteristics to produce the east Asian hair form. Hum Mutat. 2008:29:1405-11.

12. Cluzeau C, Hadj-Rabia S, Bal E, Clauss F, Munnich A, Bodemer C, et al. The EDAR370A allele attenuates the severity of hypohidrotic ectodermal dysplasia caused by EDA gene mutation. Br J Dermatol. 2012;166:678-81.

13. Schneider H, Faschingbauer F, Schuepbach-Mallepell S, Körber I, Wohlfart S, Dick A, et al. Prenatal correction of X-linked hypohidrotic ectodermal dysplasia. N Engl J Med. 2018;378:1604-10.

14. Schneider H, Hammersen J, Preisler-Adams S, Huttner K, Rascher W, Bohring A. Sweating ability and genotype in individuals with X-linked hypohidrotic ectodermal dysplasia. J Med Genet. 2011;48:426-32.

15. Hammersen JE, Neukam V, Nüsken KD, Schneider H. Systematic evaluation of exertional hyperthermia in children and adolescents with hypohidrotic ectodermal dysplasia: an observational study. Pediatr Res. 2011;70:297-301.

16. Dietz J, Kaercher T, Schneider AT, Zimmermann T, Huttner K, Johnson R, et al. Respiratory and ocular involvement in X-linked hypohidrotic ectodermal dysplasia. Eur J Pediatr. 2013;172:1023-31.

17. Kaercher T, Dietz J, Jacobi C, Berz R, Schneider H. Diagnosis of X-linked hypohidrotic ectodermal dysplasia by Meibography and infrared thermography of the eye. Curr Eye Res. 2015;40:884-90.

18. Wahlbuhl-Becker M, Faschingbauer F, Beckmann MW, Schneider $\mathrm{H}$. Hypohidrotic ectodermal dysplasia: breastfeeding complications due to impaired breast development. Geburtshilfe Frauenheilkd. 2017;77:377-82.

19. Wünsche $S$, Jüngert J, Faschingbauer $F$, Mommsen $H$, Goecke T, Schwanitz $K$, et al. Noninvasive prenatal diagnosis of hypohidrotic ectodermal dysplasia by tooth germ sonography. Ultraschall Med. 2015;36:381-5.

20. Burger K, Schneider AT, Wohlfart S, Kiesewetter F, Huttner K, Johnson R, et al. Genotype-phenotype correlation in boys with X-linked hypohidrotic ectodermal dysplasia. Am J Med Genet A. 2014;164:2424-32.

21. Neuhauser H, Schienkiewitz A, Schaffrath Rosario A, Dortschy R, Kurth BM. Referenzperzentile für anthropometrische Maßzahlen und Blutdruck aus der Studie zur Gesundheit von Kindern und Jugendlichen in Deutschland (KiGGS). Beiträge zur Gesundheitsberichterstattung des Bundes. Robert Koch-Institut. Berlin. 2013;2:22-31.

22. Jakobiec FA, Iwamoto T. The ocular adnexa: lids, conjunctiva, and orbit. Ocular histology, vol. 2. New York: Harper \& Row; 1979. p. 290.

23. Miller KL, Walt JG, Mink DR, Satram-Hoang S, Wilson SE, Perry HD, et al. Minimal clinically important difference for the ocular surface disease index. Arch Ophthalmol. 2010;128:94-101.

24. Hanifin JM, Thurston M, Omoto M, Cherill R, Tofte SJ, Graeber M. The eczema area and severity index (EASI): assessment of reliability in atopic dermatitis. EASI Evaluator Group Exp Dermatol. 2001;10:11-8.

25. Barbier N, Paul C, Luger T. Validation of the eczema area and severity index for atopic dermatitis in a cohort of 1550 patients from the Pimecrolimus cream $1 \%$ randomized controlled clinical trials programme. $\mathrm{Br} J$ Dermatol. 2003;150:96-102

26. Chopra R, Vakharia PP, Sacotte R. Severity strata for EASI, mEASI, OSCORAD, SCORAD, ADSI and BSA in adilescents and adults with atopic dermatitis. Br J Dermatol. 2017;177:1316-21.

27. Knop E, Knop N, Millar T, Obata H, Sullivan DA. The international workshop on Meibomian gland dysfunction: report of the subcommittee on anatomy, physiology, and pathophysiology of the Meibomian gland. Invest Ophthalmol Vis Sci. 2011;52:1938-78.

28. Fete M, Hermann J, Behrens J, Huttner KM. X-linked hypohidrotic ectodermal dysplasia (XLHED): clinical and diagnostic insights from an international patient registry. Am J Med Genet A. 2014;164:2437-42.
29. Motil KJ, Fete TJ, Fraley JK, Schultz RJ, Foy TM, Ochs U, et al. Growth characteristics of children with ectodermal dysplasia syndromes. Pediatrics. 2005; 116:e229-34

30. Pinheiro M, Ideriha MT, Chautard-Freire-Maia EA, Freire-Maia N, Primo-Parmo SL. Christ-Siemens-Touraine syndrome. Investigations on two large brazilian kindreds with a new estimate of the manifestation rate among carriers. Hum Genet. 1981;57:428-31.

31. Pavlovsky M, Fuchs-Telem D, Nousbeck J, Sarig O, Sprecher E. Molecular evidence for the role of X-chromosome inactivation in linear presentation of X-linked hypohidrotic ectodermal dysplasia. Clin Exp Dermatol. 2012;37: $186-8$.

32. Lei $K$, Zhang Y, Dong Z, Sun Y, Yi Z, Chen Z. A novel 1-bp deletion mutation and extremely skewed $X$-chromosome inactivation causing severe X-linked hypohidrotic ectodermal dysplasia in a Chinese girl. Clin Exp Dermatol. 2018:43:60-2.

33. Milovidova TB, Schagina OA, Freire MV, Demina NA, Filatova AY, Skoblov MY, et al. X-linked hypohidrotic ectodermal dysplasia: clinical and molecular genetic analysis of a large Russian family with a synonymous p.Ser267= (c 801A>G) splice site mutation. J Eur Acad Dermatol Venereol. 2019;33:46870.

34. Gaide O, Schneider P. Permanent correction of an inherited ectodermal dysplasia with recombinant EDA. Nat Med. 2003:9:614-8.

35. Casal ML, Lewis JR, Mauldin EA, Tardivel A, Ingold K, Favre M, et al. Significant correction of disease after postnatal administration of recombinant ectodysplasin a in canine X-linked ectodermal dysplasia. Am J Hum Genet. 2007:81:1050-6.

36. Margolis CA, Schneider P, Huttner K, Kirby N, Houser TP, Wildman L, et al. Prenatal treatment of $\mathrm{X}$-linked hypohidrotic ectodermal dysplasia using recombinant ectodysplasin in a canine model. J Pharmacol Exp Ther. 2019; 370:806-13.

\section{Publisher's Note}

Springer Nature remains neutral with regard to jurisdictional claims in published maps and institutional affiliations.

Ready to submit your research? Choose BMC and benefit from:

- fast, convenient online submission

- thorough peer review by experienced researchers in your field

- rapid publication on acceptance

- support for research data, including large and complex data types

- gold Open Access which fosters wider collaboration and increased citations

- maximum visibility for your research: over $100 \mathrm{M}$ website views per year

At $\mathrm{BMC}$, research is always in progress.

Learn more biomedcentral.com/submission 